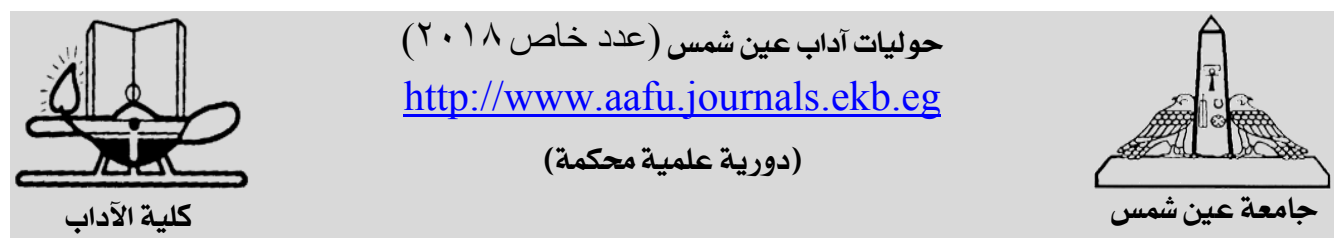

\title{
دور العجاج اللغوى فى قضية إثبات الألوهية
}

* ندا رشاد عثمان

معيدة بقسم اللغة العربية _ كلية الآداب _ جامعة عين شمس

يرتكز هذا البحث على الوسائل اللغوية التى يلقبها المرسل (المفسر) فى خطابه،

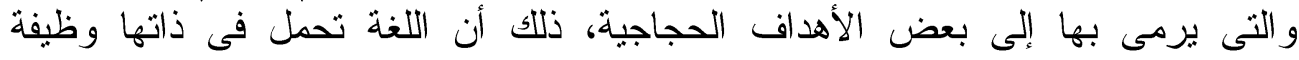
حجاجية اتخذها المفسر وسيلة لإقناع المثلقى (المنكر الغائب)، وفيما يلى سوف لإنى يتضح

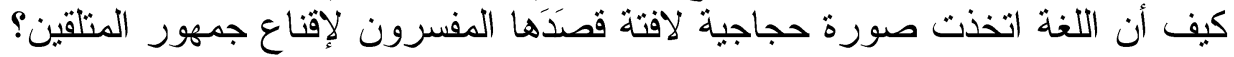


الروية الحجاجية لاى المفسرين:

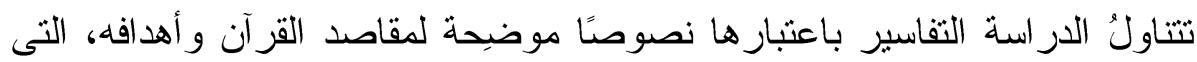

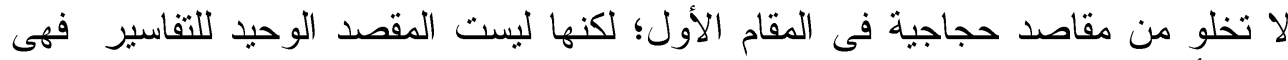

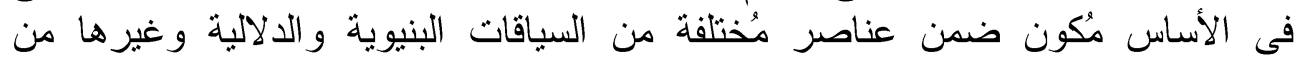
العناصر النى يقوم عليها الخطاب.

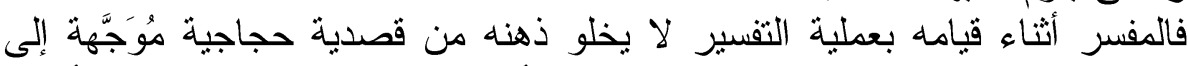

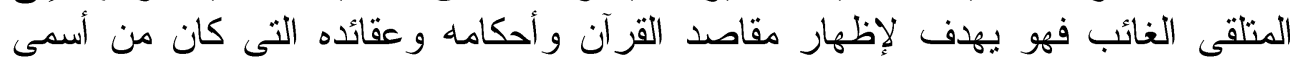

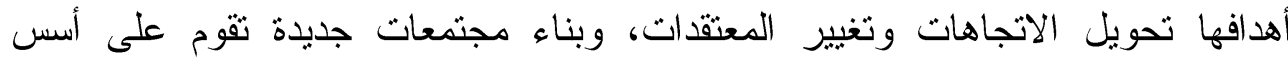

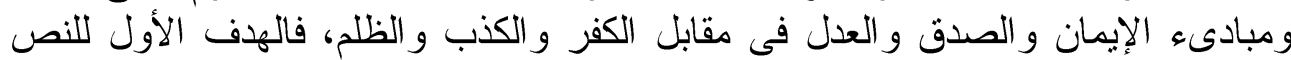

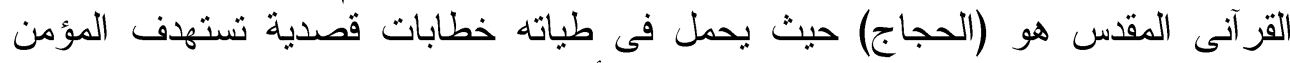

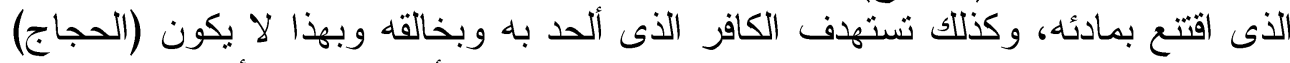

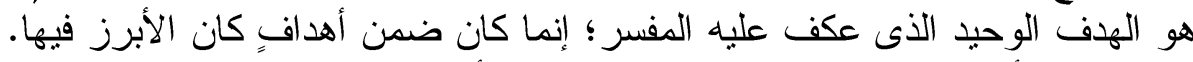

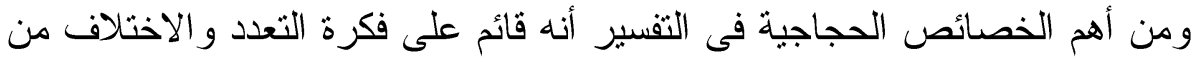

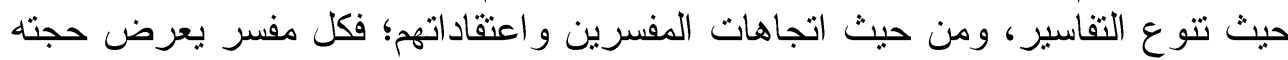

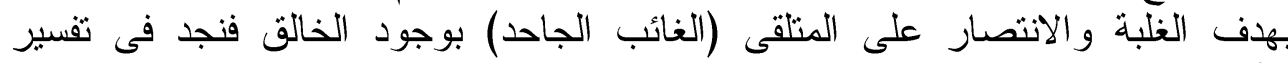

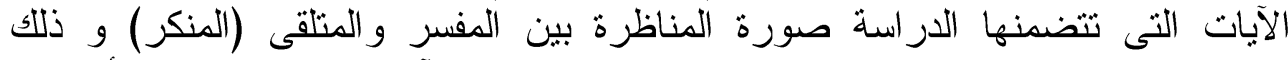

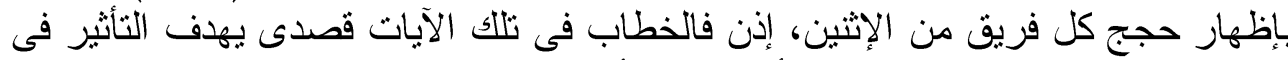

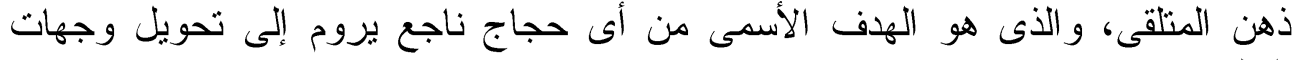
النظر - النمن

وفيما يلى سوف نقوم بتطبيق الآليات الحجاجية اللغوية على أقوال المفسرين

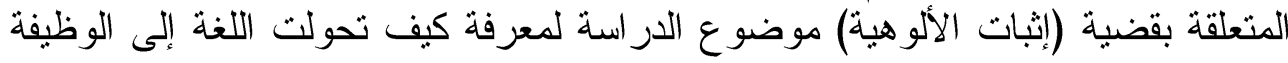

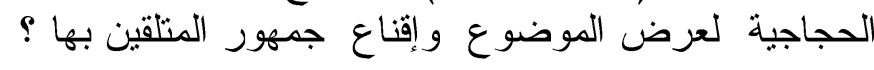




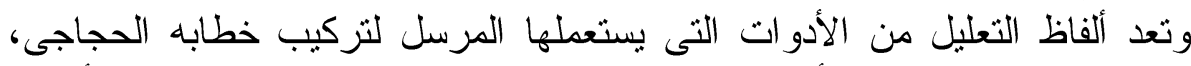

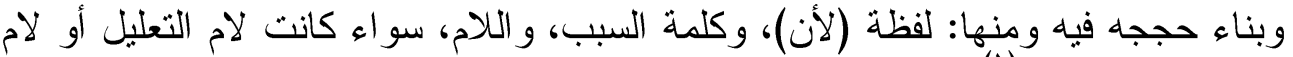

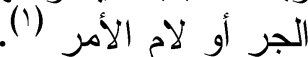

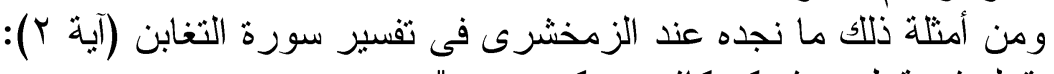

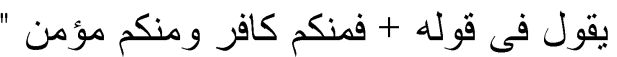

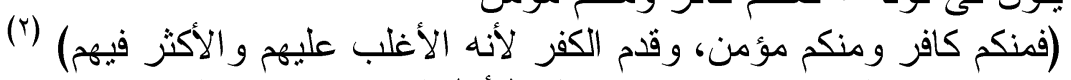

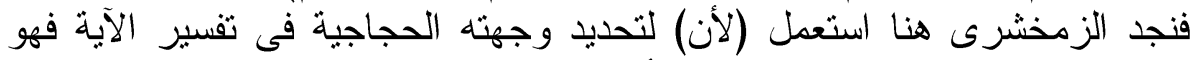

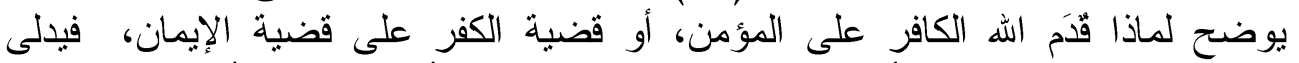

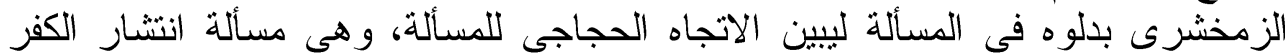

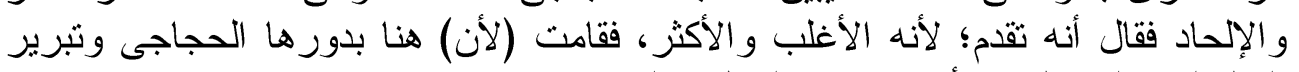

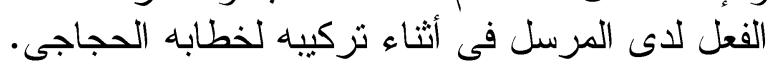

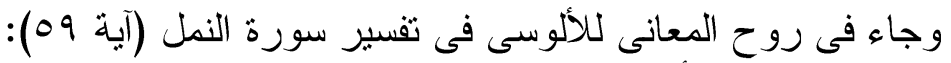

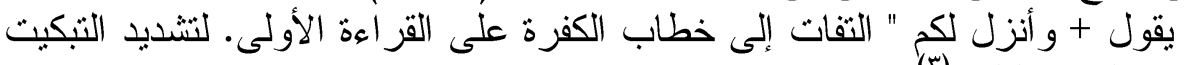
و الإلز ام، و اللام تعليلية (r).

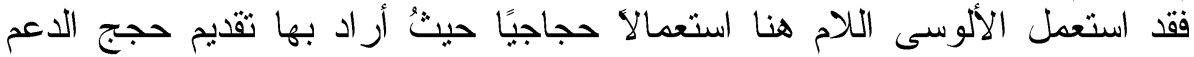

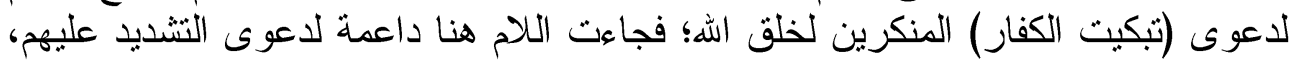
ولو لا بغية تحقيق هذه النتيجة لمًا استعملها.

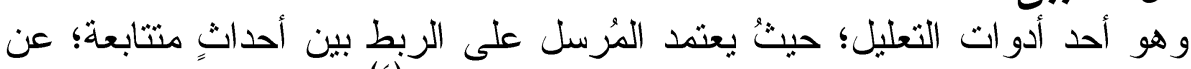

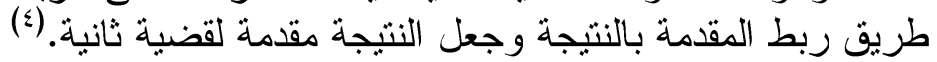

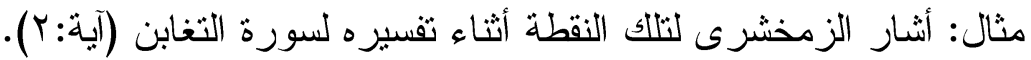

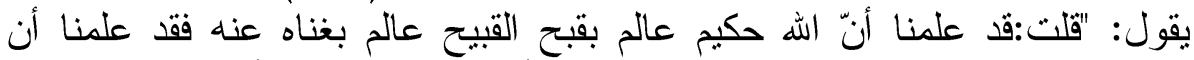

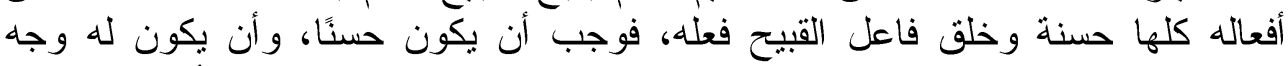

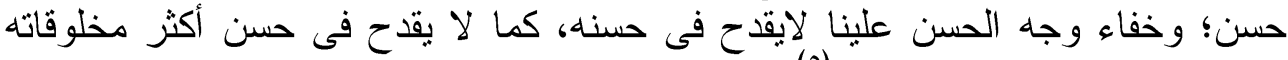

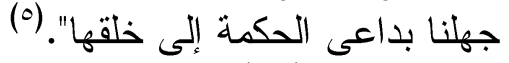
فالعلم بأن أفعال الله حسنة هو نتيجة لأن الله عالم حكيم، وهو في نفس الوقت مقدمة

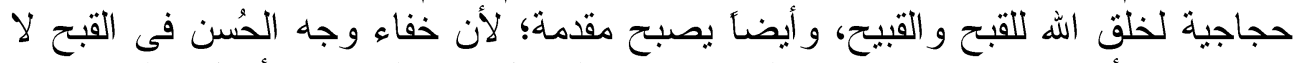

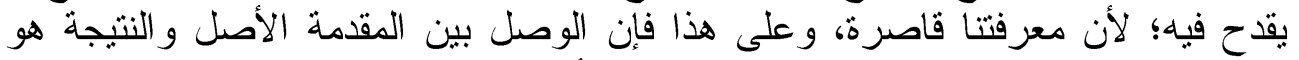

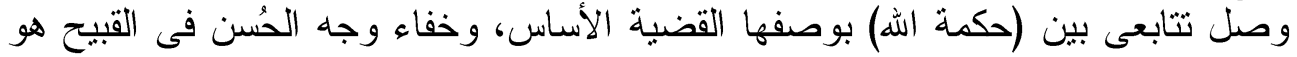
نتيجة له.

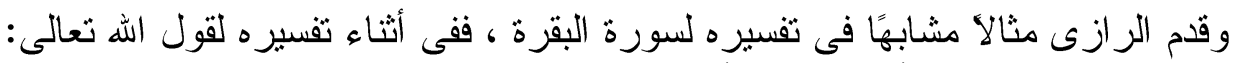

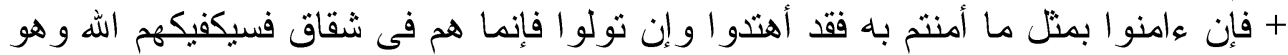

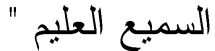

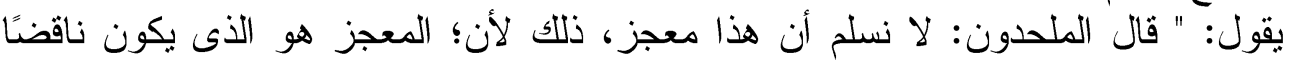

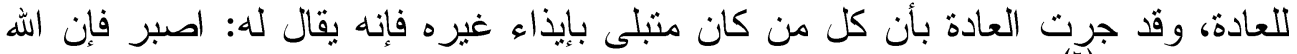

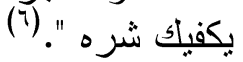




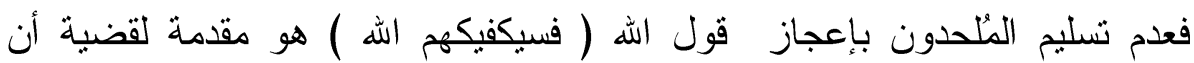

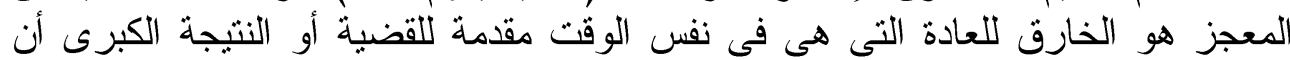

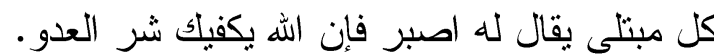

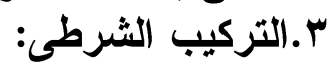

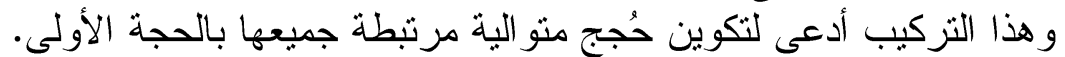

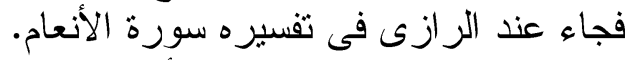

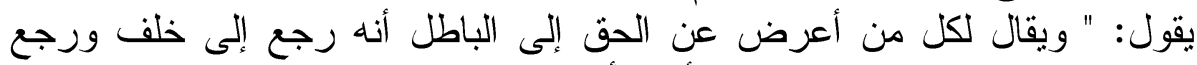

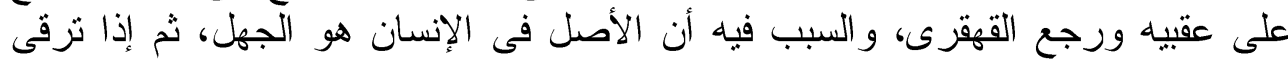

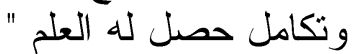
فال تعالى + و الله أخرجكم من بطون أمهاتكم لا تعلمون شينًا وجعل لكم السمع

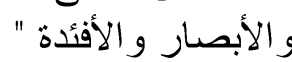

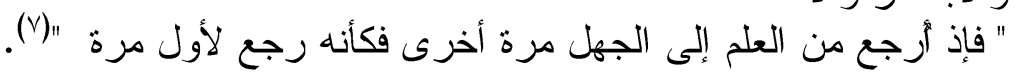

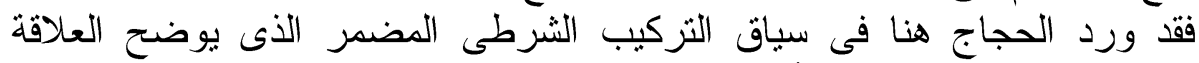

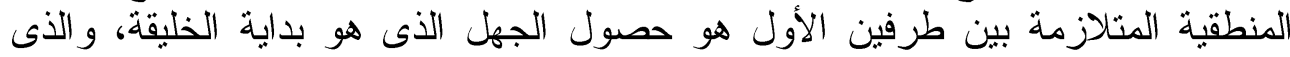

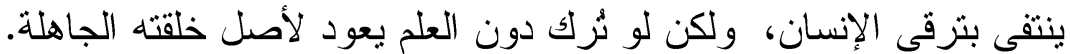

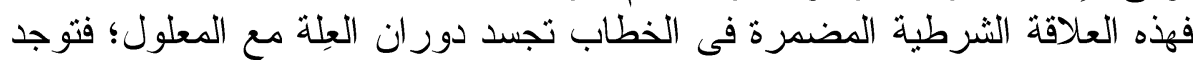

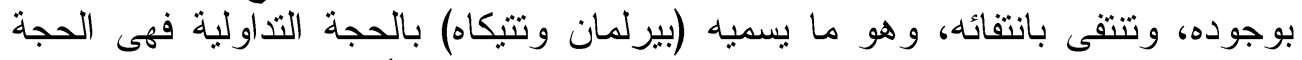

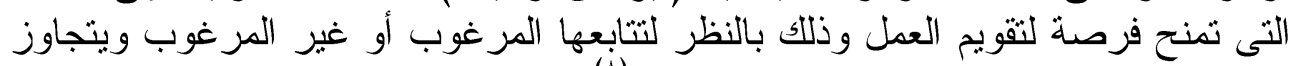

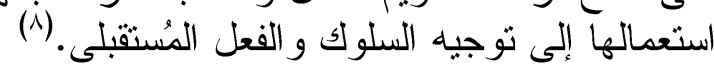

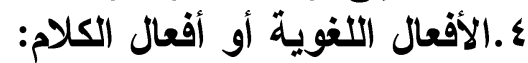

لقد سبق الإشارة إلى أنُ الأقو ال فى الألى اللغة العادية لا تستعمل للوصف أو الإخبار

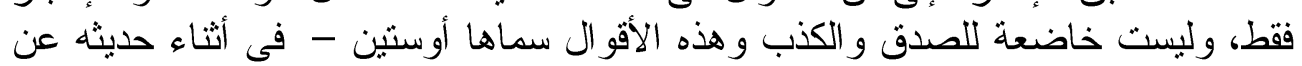

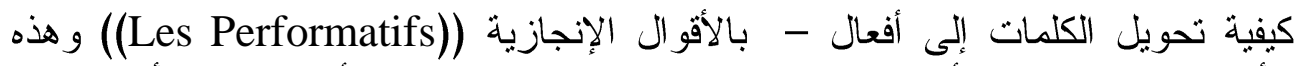

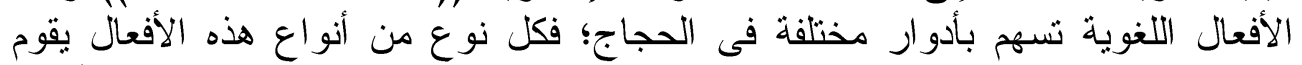

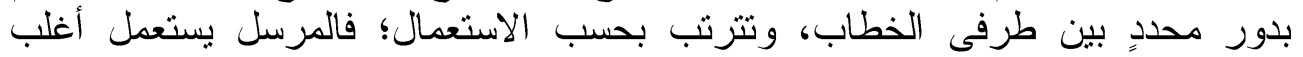

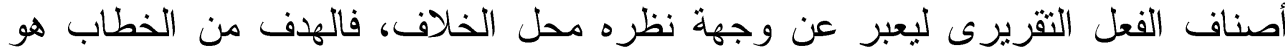

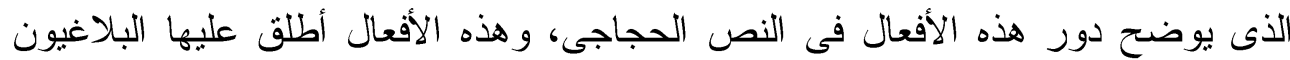

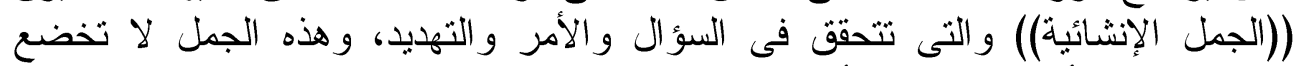

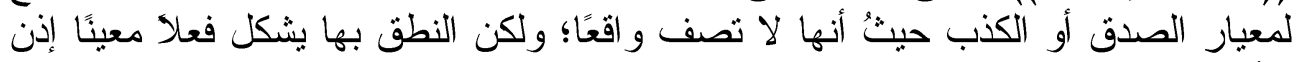

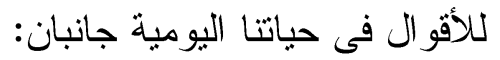

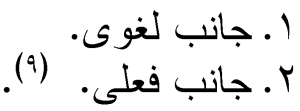
و الجمل الإنجازية يمثزج فيها القول بالفعل من أمثال:

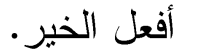

فهذه جملة إنجازية من الدرجة الأولى، حيثُ جاء فى ثناياها نشاطا فعليًا سيدفع المُرسل إلبه يقول بالفعل نظرًا لسلطة المرسل في توجيه الأل الخطاب.

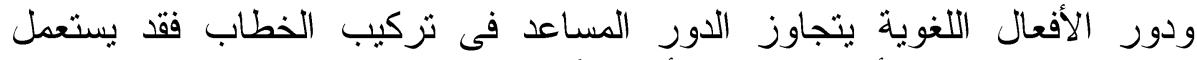

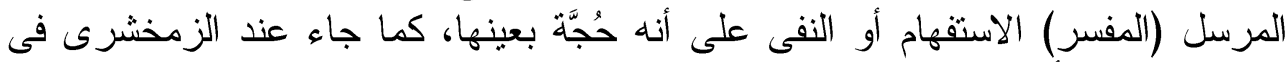
تقسيره سورة الأنبياء 


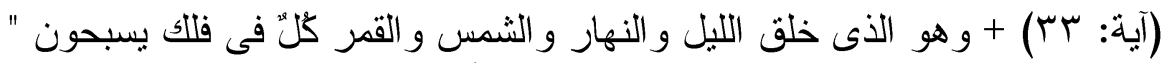

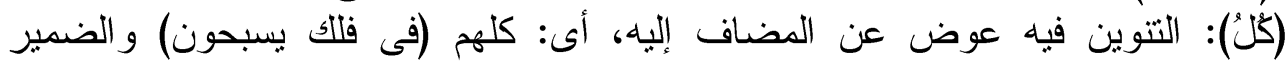

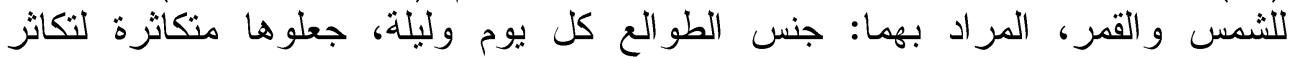

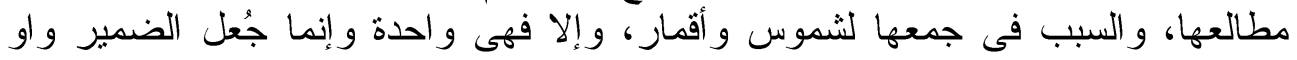

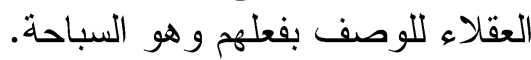
فإن قلت: الجملة ما محلها. قلت: محلها النصب على ملى الحال من الثمس و القمر .

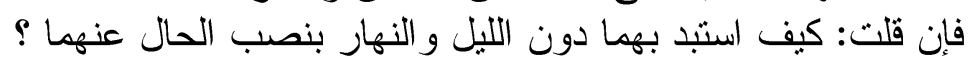

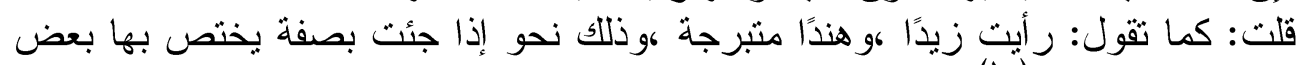

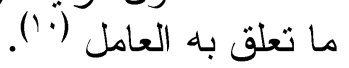

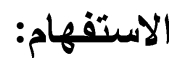

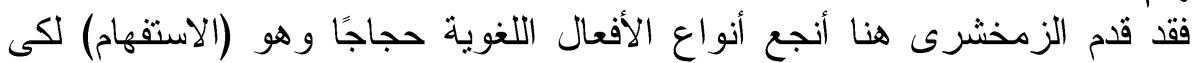

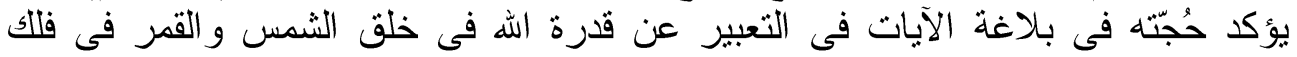

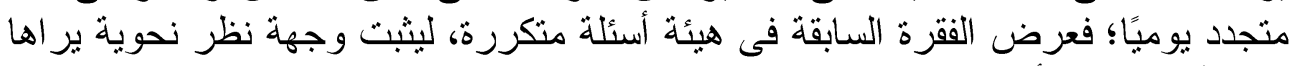

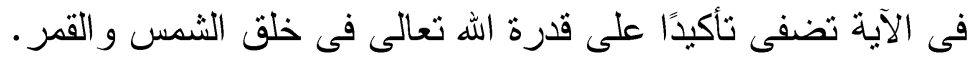

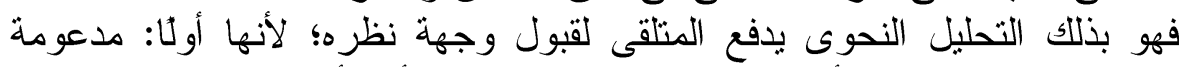

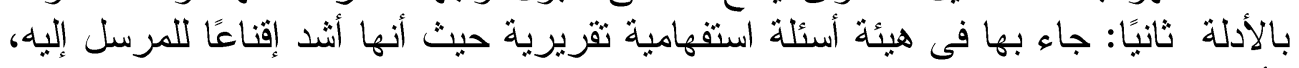

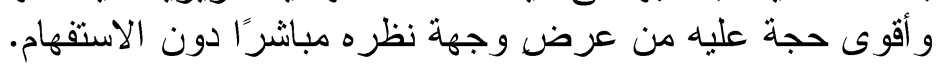
النفى: ولالنفى أيضًا نفس الدور الحجاجى الذى اضطلع به الاستقهام ففى تفسير سورة الروم (أية: إن

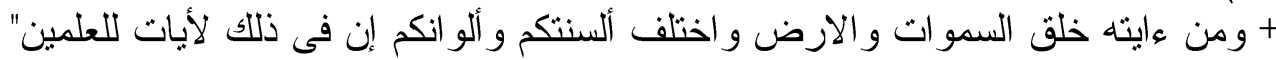

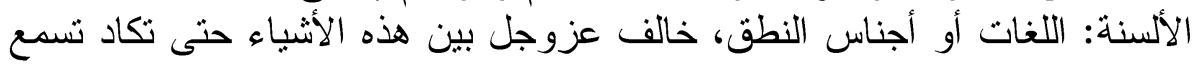

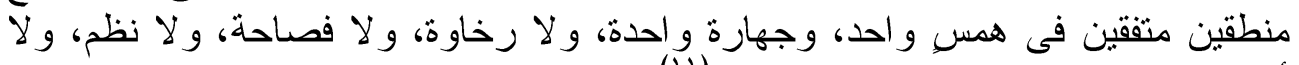
أسلوب، و لا غير ذلك من صفات النطق. (11)

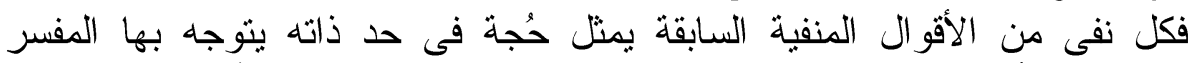

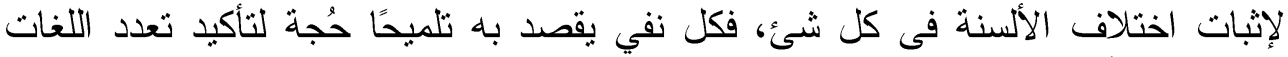

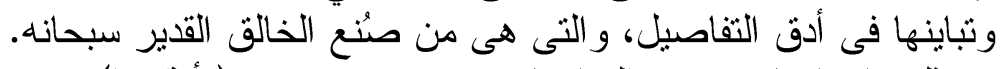

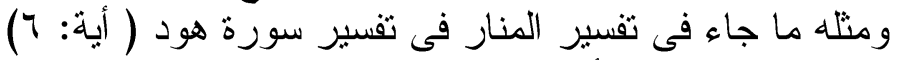

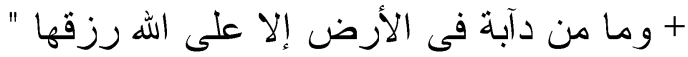

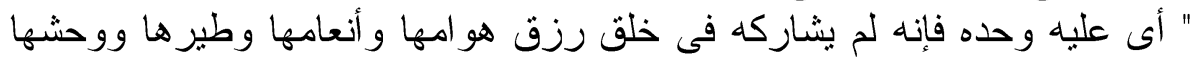

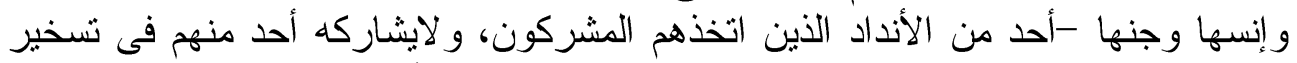

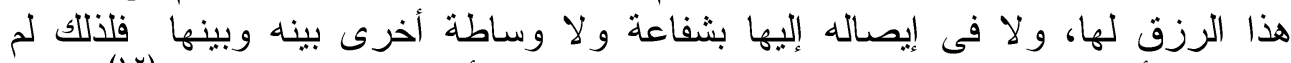

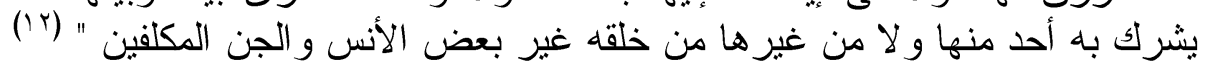

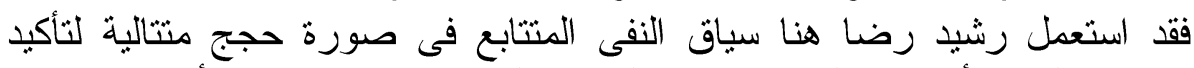

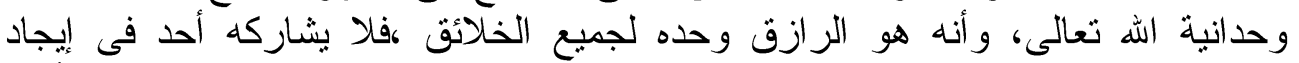
الرزق، ولا فى إيصاله لخلقه؛ لذلك هو المنفرد سبحانه بالعبادة دون غيره من الأنداد الئاد 


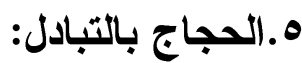

و هنا يستعمل المرسل هذه الآلية ليصف وضعًا معينًا ينتمى لسياقين منقابلين، وذلك

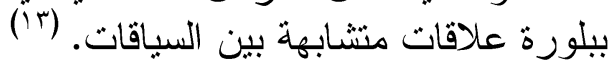

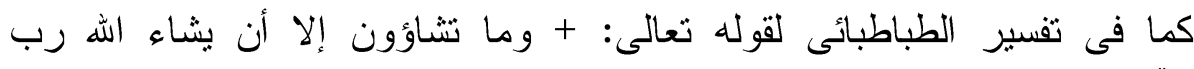

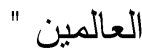
فهذه الآية دلت على أن أفعال الإنسان الإر ادية و إن كانت بيد الإنسان بإر ادته لكن

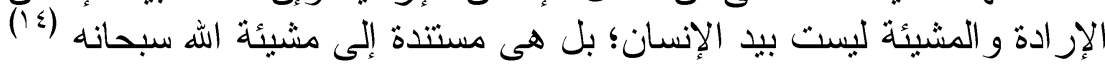

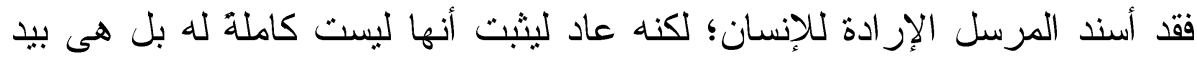
الله ثم يأمر بما بشاء فيختار الإنسان وهذا النوع من الحجج المثقابلة يوضح محل الخداد الخلاف وهى قضية (المشيئة) فقد أسند له المشيئة والاختيار ثم بسلبها منه مباشرة؛ ليؤكد على أنها ليست مطلقة

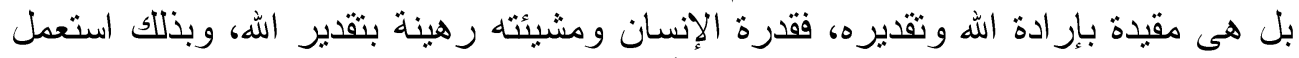

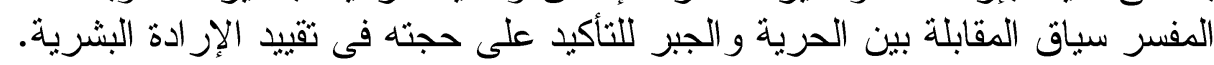
7. الوصف:

يعد الوصف من الأدوات التى تُمثل حُجَّه المرسل في خطابه، وذللك بإطلاقهه لنعتٍ

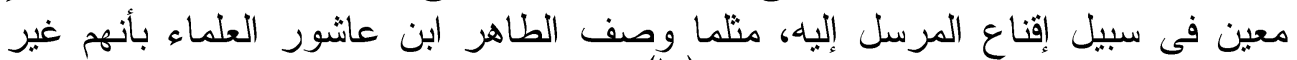

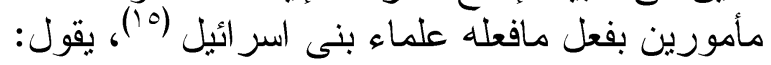

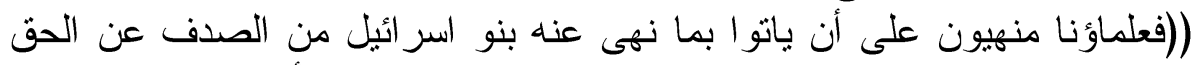

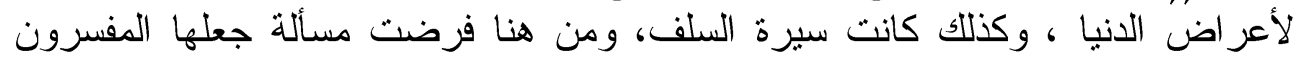

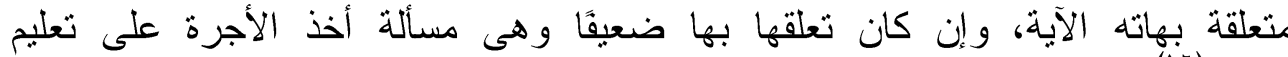
القر آن (i7)

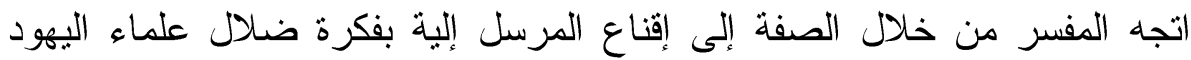

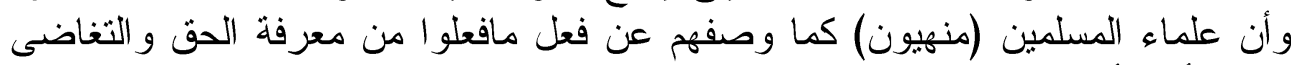

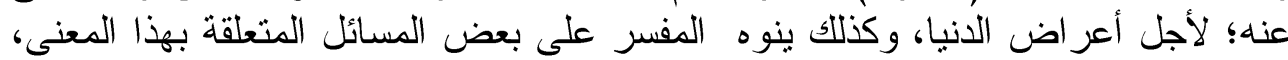

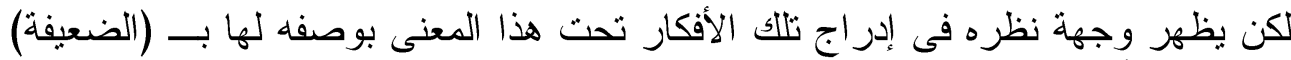

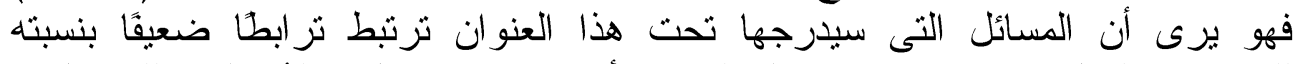

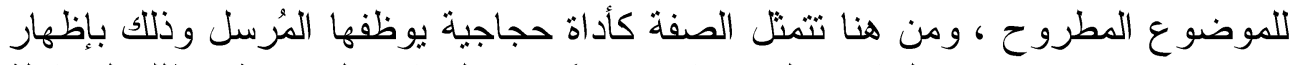

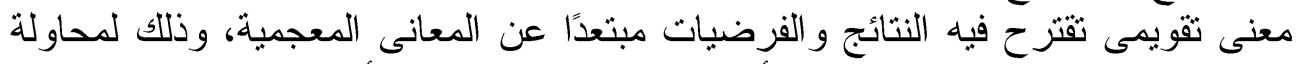

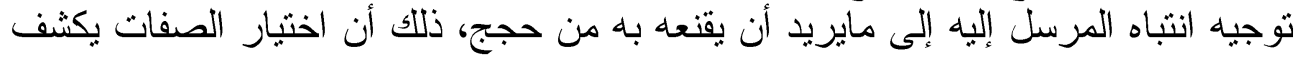

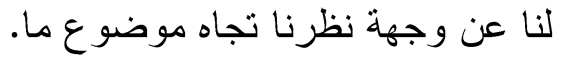

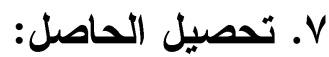

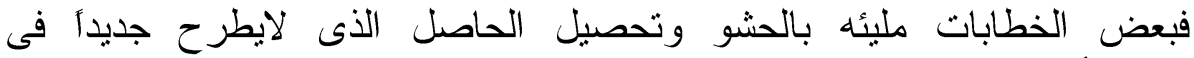

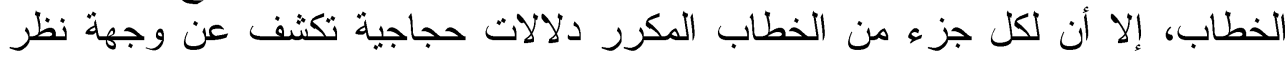

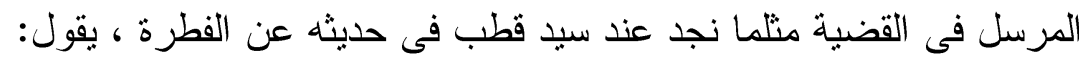
"وما المحاو لات التى تبذل لتحطيم هذة القاعدة إلا محاولة لتحطيم الفطرة البشرية

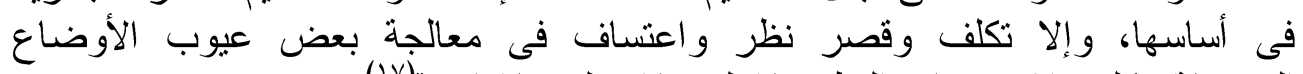

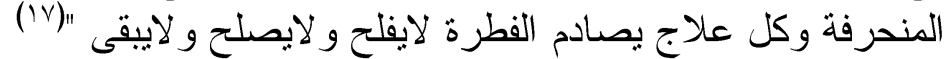

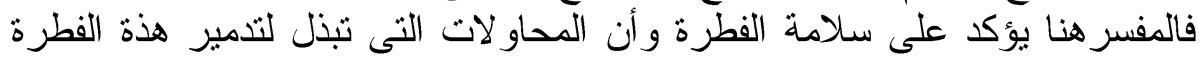

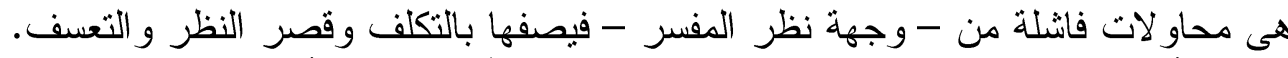
وهذة الأوصاف لتغير الفطرة ليست من سبيل التكرار أو الحشو، لأن كل كلمة منهم لها 
دلالة معينة، فالتكلف فيها إفادة للمبالغة و التهويل وأما قصر النظر فقا أفادت أن مغيرى

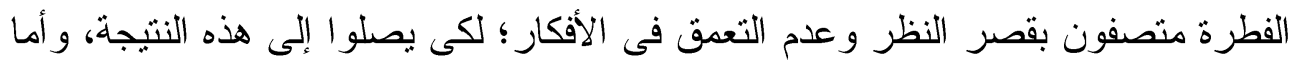

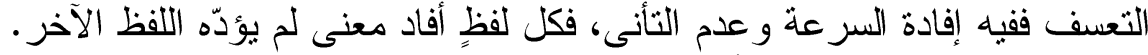

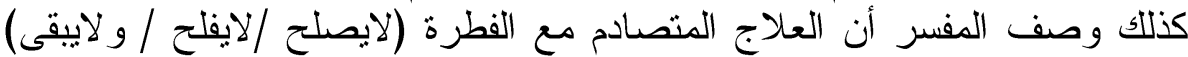

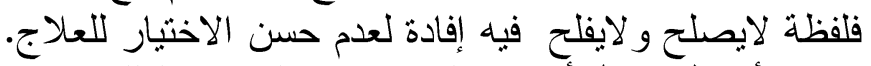

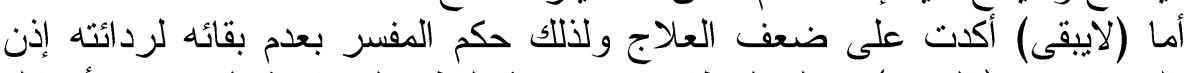

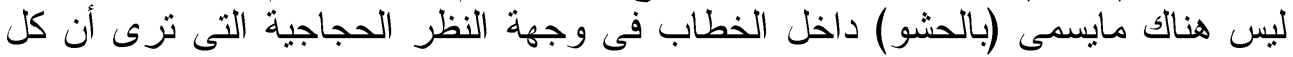

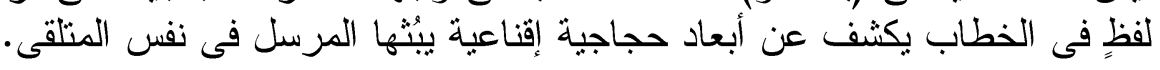




\section{Abstract}

The role of linguistic argument in proving divinity issue

\section{By Nada Rashad Osman}

This research is based on linguistic means delivered by a speaker "interpreter" in his speech to achieve some aims.

That's because the Arabic language has an argumentative function taken by an interpreter as a means to persuade the audience.

The following will show that the Arabic language has tackled argumentative matters adopted by interpreters in order to convince the audience.

$$
\begin{aligned}
& \text { الهو امش (1) }
\end{aligned}
$$

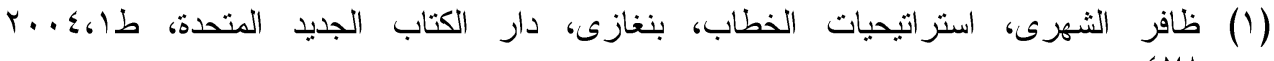

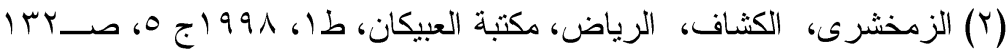

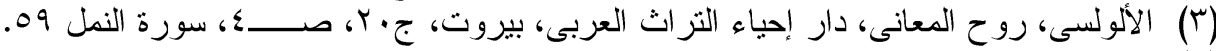

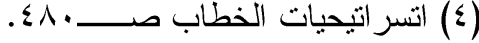

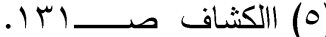

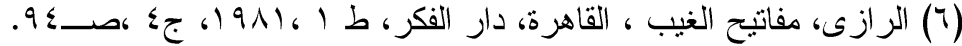

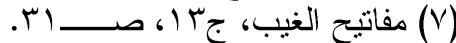

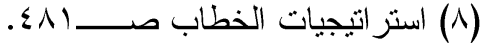

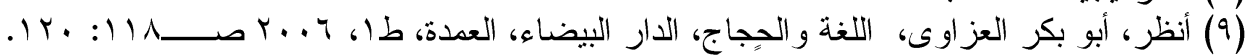

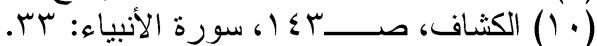

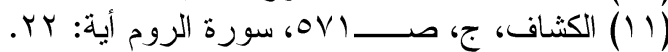

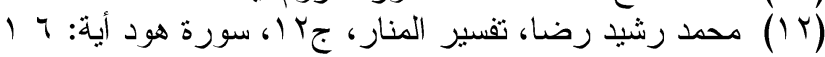

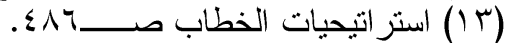

$$
\begin{aligned}
& \text { (\{ () الطباطبائى، الميزان فى تفسير القأن، بيروت، مؤسسة الأعلى للمطبوعات، طا، 1997، }
\end{aligned}
$$

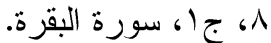

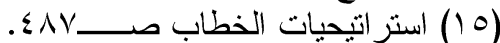

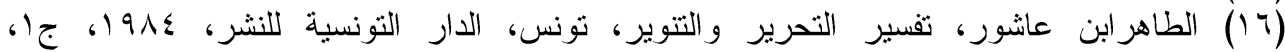

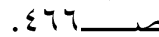

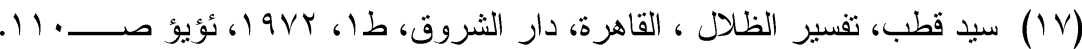

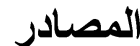

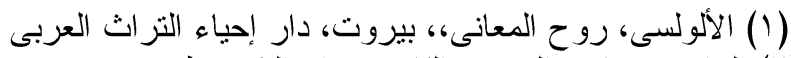

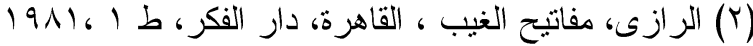

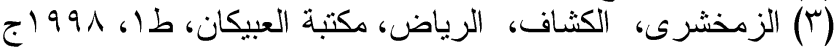

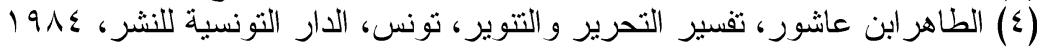

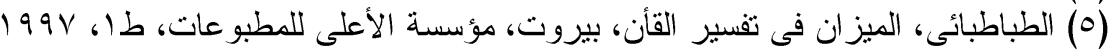

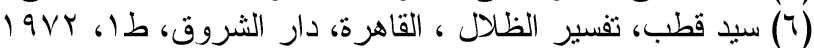

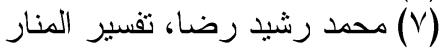

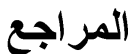

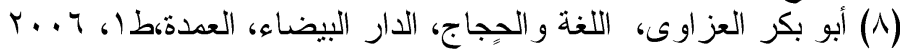

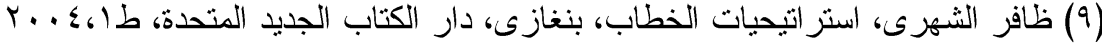

